\title{
Co-morbidities are the key nominators of the health related quality of life in mild and moderate COPD
}

\author{
Jukka Koskela ${ }^{1,5^{*}}$, Maritta Kilpeläinen ${ }^{2}$, Henna Kupiainen ${ }^{1,2}$, Witold Mazur ${ }^{1}$, Harri Sintonen ${ }^{3}$, Marike Boezen ${ }^{4}$, \\ Ari Lindqvist ${ }^{1}$, Dirkje Postma ${ }^{4}$ and Tarja Laitinen ${ }^{1,2}$
}

\begin{abstract}
Background: Co-morbidities are common in chronic obstructive pulmonary disease (COPD). We assessed the contribution of common co-morbidities on health related quality of life (HRQoL) among COPD patients.

Methods: Using both generic (15D) and respiratory-specific (AQ20) instruments, HRQoL was assessed in a hospital based COPD population ( $N=739,64 \%$ males, mean age 64 years, SD 7 years) in this observational study with inferential analysis. The prevalence of their co-morbidities was compared with those of 5000 population controls. The patients represented all severity stages of COPD and the patterns of common concomitant disorders differed between patients.

Results: Co-morbidities such as psychiatric conditions, alcohol abuse, cardiovascular diseases, and diabetes were more common among COPD patients than in age and gender matched controls. Psychiatric conditions and alcohol abuse were the strongest determinants of HRQoL in COPD and could be detected by both 15D (Odds Ratio 4.7 and 2.3 respectively) and $\mathrm{AQ} 20$ (OR 2.0 and 3.0) instruments. Compared to respiratory specific AQ20, generic 15D was more sensitive to the effects of comorbidities while AQ20 was slightly more sensitive for the low FEV 1 . FEV 1 was a strong determinant of HRQoL only at more severe stages of disease (FEV $1<40 \%$ of predicted). Poor HRQoL also predicted death during the next five years.
\end{abstract}

Conclusions: The results suggest that co-morbidities may impair HRQoL at an early stage of the disease, while bronchial obstruction becomes a significant determinant of HRQOL only in severe COPD.

Keywords: Generic HRQoL, Respiratory specific HRQoL, HRQoL, COPD, 15D, AQ20, Co-morbidities, Mortality

\section{Background}

Chronic obstructive pulmonary disease (COPD) is globally one of the leading causes of morbidity, disability, and mortality according to World Health Organization (http://www.who.int/respiratory/copd/en/). For decades, COPD was considered simply as a disease with progressive airflow limitation. Lately it has become obvious that COPD patients suffer simultaneously from several extra-pulmonary diseases such as cardiovascular diseases, diabetes, osteoporosis, musculoskeletal dysfunction, chronic kidney and heart failure, anxiety, depression,

\footnotetext{
* Correspondence: jukka.koskela@helsinki.fi

'Clinical Research Unit for Pulmonary Diseases and Division of Pulmonology, Helsinki University Central Hospital, Helsinki, Finland

${ }^{5}$ Research Unit for Pulmonary Diseases, Helsinki University Central Hospital,

Tukholmankatu 8C, PO Box 705, Fl-00029 HUS Helsinki, Finland

Full list of author information is available at the end of the article
}

and addiction diseases [1-5]. In several population studies both increased morbidity and mortality are associated with lung function impairment [6-13]. Furthermore, comorbidities have additional impact on health, for example the response to treatment received for coronary artery disease is worse in patients with co-existing COPD $[14,15]$. The underlying causes of multi-morbidity in COPD are still poorly understood. The co-occurrence of the diseases may appear simply due to patients' aging, or due to shared risk factors or etiological pathways. The latter is compatible with the hypothesis that COPD sustains systemic inflammation in the body [4].

Spirometry alone is not enough in clinical practice to predict the future outcome of COPD as for instance exacerbation rates and co-morbidity may contribute as well [16]. This has initiated studies to develop a multidimensional 
score with a better predictive power to monitor progression of COPD than $\mathrm{FEV}_{1}$ alone. Health related quality of life (HRQoL) has become one of the components of interest. So far our experience on HRQoL in COPD has mainly emerged from randomised clinical trials in which HRQoL is frequently evaluated as a secondary end point $[17,18]$. Contrary to clinical practice, the severity of COPD is often restricted and patients with severe co-occurring diseases are under-represented or even excluded. Traditionally, the number of female patients has been limited in clinical trials as well, while it is known that this affects the prevalence of co-morbidities [19] and treatment decisions [20]. Therefore, determining the effect of co-morbidities and gender on HRQoL has become increasingly important also in real world observational studies. There is also a need for the development of programs that enhance supportive care for patients with severe COPD [21]. This is particularly important since HRQoL may offer a good outcome-measure for holistic interventional studies that take into account patient's physical, psychological, social and spiritual well-being.

In the present study we aim to estimate the contribution of common co-morbidities on self-reported HRQoL among COPD patients by using two questionnaires: the AQ20 focusing on respiratory health [22] and the 15D focusing on generic health [23]. Both questionnaires are simple and short, and can be used easily in clinical practice with high response and completion rates [24,25]. AQ20 has discriminative properties and responsiveness comparable to more complex questionnaires such as SGRQ [24], and 15D and AQ20 have convergent validity to measure HRQoL in COPD [25]. We also studied the association between HRQoL and the 5-year-mortality.

\section{Methods}

\section{Subjects}

Hospital Discharge Registries were used to identify all patients with COPD who had visited the Pulmonary Clinics of the Helsinki and Turku University Hospitals during the years 1995-2006. The databases were screened by ICD10 code J44.8 and contained all patients between 18 to 75 years of age. The upper level was selected due to our study design, which included a 10-year follow-up. All identified patients were invited to the study without further selection. The recruitment was done through a two-phase mailing campaign, through which altogether 844 patients participated the study [26], after which their diagnosis was carefully assessed going through the medical records by a pulmonologist. This resulted in 739 confirmed COPD patients (clinical symptoms and airway obstruction according GOLD) with smoking related disease. The enrolment occurred during the years 2005-2007. All the participants gave informed consent to collect, merge, and analyse their comprehensive medical history from all the healthcare providers who had treated them during the past 5-10 years. Participants of the Health2000 survey $(\mathrm{N}=5000)$ were used as age and gender matched population controls to avoid biased inferences. Their diagnostic data had been gathered from the hospital discharge registries (http://www.terveys2000.fi/indexe.html).

\section{Assessment of HRQoL}

The HRQoL was assessed using the self-administered Airways Questionnaire 20 [27] and 15D (http://www.15dinstrument.net/15D). All participants filled in both questionnaires during the research visit without any guidance from the research personnel. The AQ20 questionnaire was used as the disease-specific instrument of HRQoL. This questionnaire was developed in 1998 for use in asthma [27] and COPD $[22,28]$. The AQ20 is a uni-dimensional measure containing 20 items with "yes" responses are scored as 1 , and "no" and "not applicable" are scored as 0 . The scores of 1 are summed up to obtain the AQ20 summary score, which ranges from 0 to 20 , a score of zero indicating no respiratory symptoms or worries about the disease. The 15D-instrument [29] is a generic, multidimensional, standardized, self-administered evaluative tool of HRQoL that can be used primarily as a single index measure, but also as a profile measure. It describes the health status, with 15 dimensions, namely: mobility, vision, hearing, breathing, sleeping, eating, speech, excretion, usual activities, mental function, discomfort and symptoms, depression, distress, vitality, and sexual activity. Each dimension comprises one question on a 5-point scale. A single index score is obtained by incorporating population-based preference weights to the 15 dimensions. The maximum score is 1 (no problems on any dimension) and the minimum score is 0 (being dead). The $15 \mathrm{D}$ instrument has good test-retest reliability, construct validity, and discriminatory power in general populations [23] and has been validated for use in COPD [30,31]. All participants returned the questionnaire at the recruitment session. There was no missing data for AQ20, for $15 \mathrm{D}$ eight patients did not finish the questionnaire completely and this data was omitted from analysis. Recall bias was not assessed in this study.

\section{Physiological measurements and co-morbid conditions}

All hospitals, health care centres, and other outpatient clinics that had treated the patients were contacted to archive a complete medical history for each participant. The patients' social security number was used to combine the data from different sources. Source data with personal identifiers were managed and stored in the Clinical Research Centres administered by the Helsinki and Turku University Central Hospitals. The results of flow-volume spirometry including bronchodilatation tests nearest to index date, diffusion capacity, ECGs at rest, weight, height 
and smoking status were used in the analysis. The reference values used for $\mathrm{FEV}_{1}$ and FVC in Finnish clinical practice were validated in large Finnish population samples consisting of both genders and a wide range of age groups [32]. All the given diagnoses stated in the medical records were carefully evaluated; especially concerning the time of onset and certainty of the diagnosis was determined. Category 'coronary disease' included the patients who have had a myocardial infarction, acute coronary artery syndrome, or angina pectoris diagnosed by an internist or cardiologist. 'Cerebrovascular diseases' included patients with strokes and transient ischemic attacks diagnosed by a neurologist. 'Cardiovascular diseases' consisted of patients having one of the following diseases: coronary, cerebrovascular disease, or peripheral artery occlusive disease. Chronic atrial fibrillation was confirmed by ECG recordings. Category 'diabetes' includes patients with the type 1 and 2 disease. Chronic alcoholism, alcohol use disorder, and treatment of alcohol-use related disorders were categorized as 'alcohol abuse'. A wide range of psychotic disorders and long lasting clinical depression, and anxiety that needed regular medication were categorized as 'Psychiatric condition'. Category 'cancer' included all malignant solid tumours and malignant haematological diseases. The prevalence of the common co-existing diseases were compared with an age and gender matched control population from a Finnish population survey (Health 2000, $\mathrm{N}=5000$ ) [33]. Diffusing capacity and ECG were available from a limited number of the patients and therefore excluded from the multivariate regression analyses (Table 1 and Additional file 1: Table S3). The modified Medical Research Council (mMRC) dyspnoea scale was used to measure subjective breathlessness [34].

The Coordinating Ethics Committee of the Helsinki and Uusimaa Hospital District approved the study approach, and the permission to conduct this research was granted by the Helsinki and Turku University Hospitals. All the clinical studies, sample collection and storage, and data gathering processes were done according to the standardised operational procedures (SOPs), the training of the study personnel has been documented and done according to good clinical practice. Clinical study processes have been monitored after enrolment and after each annual follow-up contact with the study subject.

\section{Statistical analysis}

Analyses were performed by the statistical software packages SPSS (IBM Corp. Released 2011. IBM SPSS Statistics for Windows, Version 20.0. Armonk, NY: IBM Corp) and R Statistical Software (R Development Core Team (2008), R version 2.15, http://www.R-project.org).

Correlations of $15 \mathrm{D}$ and AQ20 scores with lung function measurements were analysed using the Spearman correlation coefficient. Both HRQoL scores were analysed as continuous and as categorised variables. Analysis of continuous endpoints enables inferences throughout the scale of HRQoL, while categorised endpoints only compare differences between two groups. Thus parallel analysis of categorised and continuous endpoints was used as supportive approach to confirm congruent results. Linear regression was used to determine clinically valid attributes potentially affecting $\mathrm{HRQOL}$ and to compare their relative importance. Regression coefficient $\mathrm{B}$ is the change in HRQoL when dependent variable changes with one unit. To quantify the effect of a particular dependent variable we determined standardized regression coefficient $\beta$, which is a modification of $\mathrm{B}$. The effect is standardized from -1 to 1 allowing solid comparison between the variables. Differences in means of $\mathrm{FEV}_{1} \%$ of predicted were determined using ANOVA combined with Tukey's Honestly Significant Difference.

The $10.0 \%$ (in 15D) and $12.4 \%$ (closest discrete value to $10 \%$ in $\mathrm{AQ} 20$ ) of patients having the lowest HRQoL score formed the low-HRQoL subgroup. Logistic backwards-stepwise regression was used to determine the independent risk factors for low HRQoL. All covariates presented as crude ORs (Tables 1 and 2) were included into backwards-stepwise logistic regression to construct a multivariate model defining independent risk factors for poor HRQoL. The model constructed for poor $15 \mathrm{D}$ was then used to assess its performance in predicting 5 -year mortality by determining Receiver Operating Characteristic (ROC) and Area Under the Curve (AUC). The Minimal Clinically Important Difference (MCID) in 15D total score is 0.03 [35]. Analyses were done separately for both $15 \mathrm{D}$ (Table 2) and AQ20 (Table 1).

\section{Results}

\section{Study subjects}

A total of 739 eligible patients (64\% male, mean age 64 \pm SD 7 years, mean pack years $51 \pm$ SD 20) with COPD attended the study. The patients were identified through a two-phase mailing campaign, which was directed to all elderly asthma, and COPD patients who had visited the University Hospital of Helsinki and Turku years 19952006 [26]. The diagnosis was made on average 5.5 years before the enrolment. The severity of the disease was determined by the latest flow volume spirometry, which was performed within two years before the recruitment. According to the GOLD criteria [36], the majority of the patients belonged to the stages $2-3$, moderate to severe COPD.

Even though women had slightly better lung function (mean $\mathrm{FEV}_{1} 55$ vs. $61 \%$ of predicted, $\mathrm{p}<0.001$ ), they reported higher scores for several questions related to respiratory symptoms and the mean AQ20 summary score was significantly higher among women than men (7.9 vs. 8.8 
Table 1 Risk factors for low HRQoL (AQ20 summary score $\geq 14$ ) based on univariate and backwards-stepwise multivariate regression analysis

\begin{tabular}{|c|c|c|c|c|c|c|c|c|}
\hline Patient characteristics & $\begin{array}{l}\mathrm{N} \text { of patients } \\
\text { analyzed }\end{array}$ & $\begin{array}{l}\text { \% patients with } \\
\text { poor HRQoL }\end{array}$ & Crude OR & $95 \% \mathrm{Cl}$ & P-value & Adjusted OR & $95 \% \mathrm{Cl}$ & P-value \\
\hline \multicolumn{9}{|l|}{ Gender } \\
\hline Male & 422 & 10.8 & 1.00 & & & & & \\
\hline Female & 225 & 15.4 & 1.51 & $0.97-2.35$ & NS & 2.11 & $1.27-3.51$ & 0.004 \\
\hline \multicolumn{9}{|l|}{ Age at recruitment } \\
\hline$<60$ years & 215 & 13.5 & 1.00 & & & & & \\
\hline $61-68$ years & 274 & 14.2 & 1.06 & $0.64-1.79$ & NS & & & \\
\hline$>69$ years & 250 & 9.6 & 0.68 & $0.38-1.21$ & NS & & & \\
\hline \multicolumn{9}{|l|}{$\mathrm{FEV}_{1}$ baseline $\%$ of predicted } \\
\hline$>80$ & 95 & 9.5 & 1.00 & & & & & \\
\hline $65-80$ & 185 & 4.9 & 0.50 & $0.17-1.43$ & NS & 0.54 & $0.18-1.63$ & 0.27 \\
\hline $40-64$ & 323 & 13.3 & 1.47 & $0.63-3.43$ & NS & 2.48 & $0.99-5.95$ & 0.05 \\
\hline$<40$ & 136 & 22.9 & 2.84 & $1.19-6.79$ & 0.02 & 5.17 & $2.03-13.17$ & 0.001 \\
\hline \multicolumn{9}{|l|}{ Smoking cessation succeed } \\
\hline Yes & 358 & 11.2 & 1.00 & & & & & \\
\hline No & 281 & 14.2 & 1.32 & $0.83-2.11$ & NS & & & \\
\hline \multicolumn{9}{|l|}{ BMI units } \\
\hline$<19$ & 33 & 34.3 & - & - & - & & & \\
\hline $19-25$ & 251 & 4.5 & 1.00 & & & & & \\
\hline$>25-30$ & 275 & 37.6 & 0.64 & $0.37-1.07$ & NS & & & \\
\hline$>30$ & 173 & 23.6 & 0.95 & $0.54-1.64$ & NS & & & \\
\hline \multicolumn{9}{|l|}{ Diabetes } \\
\hline No & 628 & 11.9 & 1.00 & & & & & \\
\hline Yes & 111 & 15.3 & 1.33 & $0.75-2.36$ & NS & & & \\
\hline \multicolumn{9}{|l|}{ Cardiovascular Disease $^{1}$} \\
\hline No & 532 & 13.3 & 1.00 & & & & & \\
\hline Yes & 207 & 10.1 & 0.73 & $0.44-1.23$ & NS & & & \\
\hline \multicolumn{9}{|l|}{ Hypertension } \\
\hline No & 439 & 12.3 & 1.00 & & & & & \\
\hline Yes & 300 & 12.7 & 1.03 & $0.66-1.61$ & NS & & & \\
\hline Atrial Fibrillation & & & & & & $--^{2}$ & & \\
\hline No & 474 & 14.1 & 1.00 & & & & & \\
\hline Yes & 31 & 29.0 & 2.49 & $1.10-5.63$ & 0.03 & & & \\
\hline \multicolumn{9}{|l|}{ Diffusing capacity } \\
\hline Normal & 221 & 11.8 & 1.00 & & & & & \\
\hline Mild/moderately decrease & 89 & 11.2 & 0.95 & $0.44-2.06$ & NS & & & \\
\hline Severe decrease & 103 & 16.5 & 1.48 & $0.77-2.87$ & NS & & & \\
\hline \multicolumn{9}{|l|}{ Cancer } \\
\hline No & 695 & 12.4 & 1.00 & & & & & \\
\hline Yes & 44 & 13.6 & 1.12 & $0.46-2.72$ & NS & & & \\
\hline \multicolumn{9}{|l|}{ Psychiatric conditions } \\
\hline No & 493 & 9.9 & 1.00 & & & & & \\
\hline Yes & 240 & 17.1 & 1.87 & $1.19-2.92$ & 0.006 & 1.99 & $1.21-3.29$ & 0.007 \\
\hline
\end{tabular}


Table 1 Risk factors for low HRQoL (AQ20 summary score $\geq 14$ ) based on univariate and backwards-stepwise multivariate regression analysis (Continued)

\begin{tabular}{|c|c|c|c|c|c|c|c|c|}
\hline \multicolumn{9}{|c|}{ Alcohol abuse } \\
\hline No & 629 & 10.5 & 1.00 & & & & & \\
\hline Yes & 110 & 23.6 & 2.64 & $1.59-4.39$ & $<0.001$ & 3.02 & $1.65-5.51$ & 0.001 \\
\hline
\end{tabular}

Odd Ratios with $P$ values $\leq 0.05$ are shown in bold

${ }^{1}$ coronary, cerebrovascular, or peripheral artery disease, ${ }^{2}$ due to small number of tested patients not included to the multivariate analysis.

$\mathrm{p}=0.02$ ) (Additional file 1: Table S2). For 15D the total score did not differ (0.79 for both sexes). Women, however, reported more difficulties with sleep, depression, and distress than men. Men suffered more frequently from impairment of sexual performance than women (Additional file 1: Table S1).

\section{Co-morbidities in the cohort}

Common co-morbidities of the COPD patients were evaluated from the medical records (Table 3). Cardiovascular diseases, diabetes, and chronic psychiatric conditions were more prevalent in the COPD cohort than among the gender and age matched Finnish controls.

The prevalence of co-occurrence of the chronic medical conditions was comparable in males and females, no comorbidities $27.9 \%$ vs. $26.3 \%, 1$ co-morbidity 31.5 vs. $31.9 \%$, 2 co-morbidities $21.4 \%$ vs. $26.3 \%$, 3 co-morbidities $14.6 \%$ vs. $11.7 \%$ and $\geq 4$ co-morbidities $4.7 \%$ vs. $3.8 \%$ respectively. The number of chronic conditions did not significantly associate with $\mathrm{FEV}_{1}$ levels.

\section{Lung function and co-morbidities in relation to HRQoL scores}

Both $\mathrm{FEV}_{1}$ and diffusing capacity correlated with the HRQoL scores weakly or moderately, $\mathrm{FEV}_{1}$ slightly stronger than diffusing capacity and both lung function measurement slightly stronger to AQ20 than $15 \mathrm{D}$ (Table 4). The strongest correlation was found between the two HRQoL instruments $(r=-0.69)$. The lung function measures ( $\mathrm{FEV}_{1}$ and DLCOcVA) were also moderately correlated with each other $(r=0.35)$.

Only a very small proportion of variance (adjusted $\mathrm{R}^{2}$ $3.5 \%$ ) found in the $15 \mathrm{D}$ total score was explained by $\mathrm{FEV}_{1}$ and diffusion capacity alone. When co-morbidities were added into the model, psychiatric conditions, $\mathrm{FEV}_{1}$, alcohol abuse, diabetes, cardiovascular diseases, and hypertension were significant determinants of the total 15D scores. Psychiatric conditions $(\mathrm{p} \leq 0.001)$ and $\mathrm{FEV}_{1}(\mathrm{p} \leq 0.001)$ had the greatest effect $(\beta>0.2)$. Alcohol abuse $(p \leq 0.001)$, cardiovascular diseases $(\mathrm{p}=0.006)$, and diabetes $(\mathrm{p}=0.007)$ had $\beta$-values in the range of $0.1-0.2$ while hypertension $(\mathrm{p}=0.04)$ had the smallest $\beta(0.08)$. After performing stepwise regression, explained variance in $15 \mathrm{D}$ was increased considerably from $3.5 \%$ to $17.6 \%$.

Correspondingly for AQ20, the greatest effect was found for $\operatorname{FEV}_{1}(\beta=0.34, \mathrm{p}<0.001)$, while psychiatric conditions ( $\mathrm{p} \leq 0.001)$, female gender $(\mathrm{p} \leq 0.001)$, alcohol abuse $(\mathrm{p}=0.002)$ all had $\beta$-values in the range of $0.1-$ 0.2 , and hypertension had the smallest effect $(\beta<0.1, \mathrm{p}=$ $0.008)$. The model including the comorbidities explained $15.5 \%$ of the AQ20 summary score, while FEV $\mathrm{F}_{1}$ and diffusion capacity alone explained only $6.9 \%$ of the variation.

\section{Clinical variables explaining low HRQoL}

The mean 15D total score in the cohort was 0.79 (SD $0.11)$. Patients with the lowest $10 \%$ of the $15 \mathrm{D}$ score $(\mathrm{N}=$ $79 / 731,9.6 \%$ of men and $11.1 \%$ of women) formed the low $15 \mathrm{D}$ category (total score $\leq 0.65$, Table 2 ). Diabetes (OR 2.1, 95\% CI 1.1-4.2, $\mathrm{p}=0.03$ ), psychiatric conditions and alcohol abuse (OR 2.3, 95\% CI 1.2-4.5, $\mathrm{p}=0.007$ ), were independently associated with a low $15 \mathrm{D}$ score. The greatest risk of a low 15D score (OR 4.7, 95\% CI 2.6-8.4, p $\leq$ 0.001) was shown among COPD patients with psychiatric conditions. A low 15D score was significantly related to airway obstruction only when the patients' $\mathrm{FEV}_{1}$ was $<40 \%$ of predicted. The OR of low 15D score was then three-fold compared to patients with $\mathrm{FEV}_{1}>80 \%$ (95\% CI $1.1-8.6, \mathrm{p}=0.03$ ).

The mean AQ20 summary score in the cohort was $8.25(\mathrm{SD}=5.03)$. The lowest $12.4 \%$ of AQ20 (summary score $>14, \mathrm{~N}=92 / 739,12.1 \%$ of men and $18.2 \%$ of women) was associated with borderline significance to moderate airway obstruction (OR 2.5, 95\% CI 1.0-6.0, $\mathrm{p}=0.05$, when $\mathrm{FEV}_{1} 64-40 \%$ of predicted) and significantly to severe airway obstruction (OR 5.2, 95\% CI 2.013.2, $\mathrm{p} \leq 0.001$, when $\mathrm{FEV}_{1}<40 \%$ ). Alcohol abuse (OR 3.0, 95\% CI 1.7-5.5, p $\leq 0.001$ ) and psychiatric conditions (OR 2.0, 95\% CI 1.2-3.3, $\mathrm{p}=0.007$ ) were the significant co-morbidities associated with poor AQ20 alongside with female gender (OR 2.1, 95\% CI 1.3-3.5, $\mathrm{p}=0.004$ ). Contrary to $15 \mathrm{D}$, cardiovascular diseases and diabetes remained non-significant predictors for poor AQ20 score (Table 1). Thirty-three patients were categorised having low HRQoL by both questionnaires.

The mMRC dyspnoea scale did not remain significant in any of the models after stepwise model selection.

\section{Mortality and HRQoL}

In order to study the importance of the identified risk factors of low generic $\mathrm{HRQ}$ oL, the same variables were used in a 5-year mortality model $\left(\mathrm{N}_{\text {total }}=670, \mathrm{~N}_{\text {dead }}=105\right)$ (Additional file 1: Table S3). $\mathrm{FEV}_{1}<40 \%$ of predicted was 
Table 2 Risk factors for a low score on 15D (total score $\mathbf{0 . 6 5 )}$ based on univariate and backwards stepwise multivariate regression analysis

\begin{tabular}{|c|c|c|c|c|c|c|c|c|}
\hline Patient characteristics & $\mathrm{N}$ of patients analyzed & $\begin{array}{l}\text { \% patients with } \\
\text { poor HRQoL }\end{array}$ & Crude OR & $95 \% \mathrm{Cl}$ & P-value & Adjusted OR & $95 \% \mathrm{Cl}$ & $P$-value \\
\hline \multicolumn{9}{|l|}{ Gender } \\
\hline Male & 470 & 9.6 & 1.00 & & & & & \\
\hline Female & 261 & 11.1 & 1.18 & $0.72-1.93$ & NS & & & \\
\hline \multicolumn{9}{|l|}{ Age at recruitment } \\
\hline$<60$ years & 214 & 9.8 & 1.00 & & & & & \\
\hline $61-68$ years & 269 & 10.4 & 1.97 & $0.59-1.94$ & NS & & & \\
\hline$>69$ years & 248 & 10.1 & 1.03 & $0.56-1.90$ & NS & & & \\
\hline \multicolumn{9}{|l|}{$\mathrm{FEV}_{1}$ baseline $\%$ of predicted } \\
\hline$>80$ & 94 & 8.2 & 1.00 & & & 1.00 & & \\
\hline $65-80$ & 184 & 7.5 & 0.91 & $0.33-1.39$ & NS & 1.02 & $0.35-3.01$ & NS \\
\hline $40-64$ & 318 & 9.8 & 1.21 & $0.53-1.88$ & NS & 1.41 & $0.52-3.80$ & NS \\
\hline$<40$ & 135 & 16.5 & 2.21 & $0.86-5.71$ & 0.100 & 3.08 & $1.10-8.63$ & 0.03 \\
\hline \multicolumn{9}{|l|}{ Smoking cessation succeed } \\
\hline Yes & 355 & 7.9 & 1.00 & & & & & \\
\hline No & 278 & 12.6 & 1.68 & $1.00-2.84$ & 0.05 & & & \\
\hline \multicolumn{9}{|l|}{ BMI units } \\
\hline$<19$ & 32 & 9.3 & 0.65 & $0.15-2.91$ & NS & & & \\
\hline $19-25$ & 248 & 6.2 & 1.00 & & & & & \\
\hline$>25-30$ & 272 & 9.2 & 0.99 & $0.55-1.79$ & NS & & & \\
\hline$>30$ & 172 & 14.0 & 1.59 & $0.86-2.92$ & NS & & & \\
\hline \multicolumn{9}{|l|}{ Diabetes } \\
\hline No & 620 & 8.4 & 1.00 & & & 1.00 & & \\
\hline Yes & 111 & 19.8 & 2.70 & $1.56-4.66$ & $<0.001$ & 2.12 & $1.07-4.22$ & 0.03 \\
\hline \multicolumn{9}{|l|}{ Cardiovascular Disease $^{1}$} \\
\hline No & 526 & 9.1 & 1.00 & & & 1.00 & & \\
\hline Yes & 205 & 12.7 & 1.45 & $0.87-2.40$ & NS & 1.69 & $0.93-3.07$ & 0.09 \\
\hline \multicolumn{9}{|l|}{ Hypertension } \\
\hline No & 434 & 9.4 & 1.00 & & & & & \\
\hline Yes & 297 & 11.1 & 1.20 & $0.74-1.94$ & NS & & & \\
\hline \multicolumn{9}{|l|}{ Atrial Fibrillation } \\
\hline No & 468 & 11.1 & 1.00 & & & $-{ }^{2}$ & & \\
\hline Yes & 30 & 23.3 & 2.44 & $1.00-5.95$ & 0.05 & & & \\
\hline \multicolumn{9}{|l|}{ Diffusing capacity } \\
\hline Normal & 220 & 10.0 & 1.00 & & & & & \\
\hline Mild/Moderately decrease & 87 & 13.8 & 1.44 & $0.68-3.05$ & NS & & & \\
\hline Severe decrease & 102 & 11.8 & 1.20 & $0.57-2.53$ & NS & & & \\
\hline \multicolumn{9}{|l|}{ Cancer } \\
\hline No & 687 & 10.0 & 1.00 & & & & & \\
\hline Yes & 44 & 11.4 & 1.15 & $0.44-3.01$ & NS & & & \\
\hline \multicolumn{9}{|l|}{ Psychiatric conditions } \\
\hline No & 488 & 5.9 & 1.00 & & & 1.00 & & \\
\hline Yes & 237 & 18.1 & 3.51 & $2.13-5.78$ & $<0.001$ & 4.65 & $2.57-8.40$ & $<0.001$ \\
\hline
\end{tabular}


Table 2 Risk factors for a low score on 15D (total score $\mathbf{0 . 6 5}$ ) based on univariate and backwards stepwise multivariate regression analysis (Continued)

\begin{tabular}{llllllll}
\hline Alcohol abuse & & & & & & & \\
No & 621 & 8.4 & 1.00 & & & 1.00 & \\
Yes & 110 & 20.0 & $\mathbf{2 . 7 4}$ & $\mathbf{1 . 5 8 - 4 . 7 3}<\mathbf{0 . 0 0 1}$ & $\mathbf{2 . 3 3}$ & $\mathbf{1 . 2 1 - 4 . 4 9}$ & $\mathbf{0 . 0 0 7}$ \\
\hline
\end{tabular}

Odd Ratios with $P$ values $\leq 0.05$ are shown in bold.

${ }^{1}$ coronary, cerebrovascular, or peripheral artery disease, ${ }^{2}$ due to small number of tested patients not included to the multivariate analysis.

the most important risk factor (OR 6.91, 95\% CI 2.31 20.6, $\mathrm{p} \leq 0.001$ ) for mortality. Alcohol abuse (OR 2.15, 95\% CI $1.19-3.88, \mathrm{p}=0.01$ ) and cardiovascular diseases (OR 1.71, 95\% CI $1.06-2.73, \mathrm{p}=0.03$ ) were also significant risk predictors, while diabetes and psychiatric conditions remained non-significant. The model showed a substantial prognostic value of mortality (AUC $=0.70$ ). Both HRQoL scores were compromised among the patients who died compared to those who lived throughout the follow-up period (for $15 \mathrm{D}$ score 0.75 vs. 0.80 , $\mathrm{p} \leq 0.001$ and for AQ20 score 9.82 vs. 7.99, $\mathrm{p} \leq 0.001$ ).

\section{Discussion}

The present patient cohort was hospital based representing all severity stages of the disease [26]. To analyse patients' airway specific and generic HRQol we used two questionnaires. Both questionnaires are validated, well correlated and short enough to be integrated in clinical practise [25]. Our results show that cardiovascular diseases, diabetes, alcohol abuse, and different psychiatric diseases were more frequent in COPD patients than in controls. Like in previous reports, neither a particular co-morbidity nor the total number of co-morbidities correlated to the severity of airway obstruction [37]. However, co-morbidities were the most important determinants of HRQoL in subjects with mild and moderate severe obstruction. Only the presence of severe obstruction $\left(\mathrm{FEV}_{1}<40 \%\right)$ was a significant contributor of HRQoL. Using the multivariate regression models, we found that co-morbidities were associated both with general and respiratory specific HRQoL, the strongest effects being observed for psychiatric conditions that needed regular medications and alcohol abuse. The co-morbidities were diagnosed typically years before the HRQoL-measure at study baseline, and thus could be considered as risk factors of poor HRQoL. Although this suggests causality, it cannot be confirmed in this cross-sectional study. The present study cohort reflects the heterogeneity found in COPD at large. The patients represented both genders and all severity stages of airway obstruction, and various patterns of co-morbidities were present, including cardiovascular diseases, chronic atrial fibrillation, hypertension, diabetes, obesity, psychiatric conditions, cancer, and alcohol abuse, confirming previous reports on multimorbidity in COPD $[4,38]$.

Accumulation of comorbidities into the present COPD cohort was less than in some previous reports. In the present data set the diagnoses are based on retrospective medical records, but COPD patients may go under diagnosed when the symptoms of co-existing disease are not recognised or the symptoms are considered adverse events of COPD medication. Underestimation of co-existing diseases would thus weaken the role of co-morbidities explaining the variability found in HRQoL. Two to three times higher risk of cardiovascular diseases has been reported in several COPD populations [38,39]. Incompatibilities in the diagnostic criteria and differences in characteristics of COPD populations may explain to some extent the inconsistencies between studies. Preventive care for example in coronary disease has become more

Table 3 Prevalence of co-morbidities in the COPD cohort compared to those in an age and gender matched Finnish population survey

\begin{tabular}{|c|c|c|c|c|c|}
\hline \multirow[t]{2}{*}{ Chronic disease } & \multicolumn{3}{|c|}{ COPD cohort $\mathrm{N}=739$} & \multicolumn{2}{|c|}{$\begin{array}{l}\text { Finnish population cohorts health } 2000 \\
N=5000\end{array}$} \\
\hline & Men \% & Women \% & Total \% & Total \% & Difference in prevalence \\
\hline Hypertension & 41 & 40 & 41 & - & \\
\hline Coronary disease & 27 & 12 & 22 & 16 & $1.4 x$ \\
\hline Cerebrovascular disease & 9 & 5 & 8 & $5^{1}$ & $1.6 x$ \\
\hline Peripheral artery disease & 6 & 2 & 5 & 2 & $2.5 x$ \\
\hline Diabetes & 18 & 11 & 15 & 9 & $1.7 \times$ \\
\hline Alcohol abuse & 18 & 9 & 15 & - & \\
\hline Chronic psychiatric conditions & 26 & 45 & 33 & 12 & $2.8 x$ \\
\hline Cancer & 6 & 6 & 6 & 7 & $0.9 x$ \\
\hline
\end{tabular}

${ }^{1}$ stroke including also intracerebral and subarachnoidal hemorrhage. 
Table 4 Correlation matrix for lung function parameters, HRQoL, MRC Dyspnoea scale and age

\begin{tabular}{llllllll}
\hline & 15D score & Age & DLCOcVA & FEV1\% & MRC scale & FEV1*DLCOcVA & AQ20 score \\
\hline 15D Score & 1 & 0.01 & $0.11^{*}$ & $0.16^{* * *}$ & -0.03 & $0.15^{* *}$ & $-0.69^{* * *}$ \\
Age & 0.01 & 1 & -0.07 & $-0.19^{* * *}$ & 0.02 & $-0.17^{* *}$ & -0.09 \\
DLCOcVA & $0.11^{*}$ & -0.07 & 1 & $0.35^{* * *}$ & 0.03 & $0.79^{* * *}$ & $-0.19^{* * *}$ \\
FEV1\% & $0.16^{* *}$ & $-0.19^{* * *}$ & $0.35^{* * *}$ & 1 & 0.00 & $0.83^{* * *}$ & $-0.24^{* * *}$ \\
MRC Scale & -0.03 & 0.02 & 0.03 & 0.00 & 1 & 0.01 & 0.07 \\
FEV1* DLCOcVA & $0.15^{* *}$ & $-0.17^{* *}$ & $0.79^{* * *}$ & $0.83^{* * *}$ & 0.01 & 1 & $-0.25^{* * *}$ \\
AQ20 Score & $-0.69^{* * *}$ & -0.09 & $-0.19^{* * *}$ & $-0.24^{* * *}$ & 0.07 & $-0.25^{* * *}$ & 1 \\
\hline
\end{tabular}

${ }^{*} \mathrm{p}$-value $<0.05,{ }^{* *} \mathrm{p}<0.01,{ }^{* * *} \mathrm{p}<0.001$

active over time which might explain why COPD patients were at significant risk of lung cancer, heart failure, and death, but not at risk of myocardial infarction [40]. In the present COPD cohort the diagnoses were given by a specialist and gathered from medical records. The diagnoses can be considered more plausible than self-reported often used in previous reports. The prevalence may also reflect recruitment bias, i.e. if the most seriously ill patients did not participate. Excessive alcohol consumption was pronounced among COPD patients. Compared to elderly Finns in general, alcohol abuse was 4.5 fold more frequent among women and 2.3 fold more frequent among men with COPD [41]. Excess alcohol use has been found also in other COPD populations [42]. Data on chronic atrial fibrillation and diffusing capacity were not available for all, but the univariate model suggested that chronic atrial fibrillation would harm HRQoL (crude OR 2.4, 95\% CI 1.00-6.0, $\mathrm{p} \leq 0.05$ ), while impaired diffusing capacity did not. Prevalence of hypertension (41\%) and chronic atrial fibrillation (6\%) were at the same level as in general age and gender matched population in Finland [43].

Like in many previous studies, lung function alone was not a strong predictor of either respiratory or general HRQoL $[22,44,45]$. Literature on co-morbidities as determinants of HRQoL in COPD is rather sparse. Using St George's Respiratory Questionnaire (SGRQ) in primary health care COPD population $(\mathrm{N}=1817)$ it has been shown that patient with $>3$ co-morbidities had poorer HRQoL than patients with 1-2 comorbidities [46]. In patients with $<3$ co-morbidities the generic instrument was more sensitive than SGRQ suggesting that respiratory specific HRQoL is not influenced by the presence of low levels of co-morbidity. In another study ( $\mathrm{N}=326 \mathrm{COPD}$ patients) the presence of dyspnoea and exacerbation, depression was the most important contributor to HRQoL impairment measured by SGRQ, whereas other comorbidities had only limited impact [47]. When 23 co-morbid diseases were analysed in a COPD cohort $(\mathrm{N}=659$, matching age and slightly more advanced disease than in the present study), the presence of three or more co-morbid diseases was more predictive of HRQoL than any demographic variable or physiological measurement [45]. Insomnia, however, was the only separate disease that correlated to general HRQoL. In another study by Putcha et al. $(\mathrm{N}=843)$, four out of thirteen comorbid diseases (congestive heart failure, arthritis, diabetes, incontinence/prostate disease) associated independently with generic HRQoL [37]. All diagnostic information was based on self-reported data and the severity of COPD was not known in the latter study. These study designs included depression, but no other psychiatric or any addictive diseases like in our study. COPD patients in the present study displayed a large scale of psychiatric symptoms from features of psychosis to rather mild anxiety or depression. Not all of them had received a thorough psychiatric evaluation and thus the exact nature of the disease remained unknown, but the common nominator was the use of regular psychiatric medication. Psychiatric conditions (OR for low HRQoL for 15D 4.7 and for AQ20 2.0) and alcohol abuse (OR for 15D 2.3 and for AQ20 3.0) both had a strong impact on HRQoL that could be detected by generic and respiratory specific instruments. Our data also showed that diabetes affected generic HRQoL (OR 2.1) while cardiovascular diseases showed a similar trend even though not significant (OR 1.7). FEV was also a strong predictor of both generic and respiratory specific HRQoL, however the effect was significant only at late stages of disease $\left(\mathrm{FEV}_{1}<40 \%\right.$ of predicted).

Comparably with findings in the general population, cardiovascular morbidity was more prevalent among men than among women. Women reported significantly more respiratory symptoms even though their $\mathrm{FEV}_{1}$ was slightly better, as also reported earlier [48]. Regarding functional inabilities, women more often had sleeping difficulties, depression and distress while men suffered more often from impaired sexual performance.

At present, there is some evidence that HRQoL has predictive value for risk of exacerbations, use of health care resources, and mortality in COPD [49,50]. In the present study generic HRQoL was statistically $(\mathrm{p} \leq 0.001)$ and clinically (MCID >0.03) poorer among patients who died within the next five years. If the patients' 15D score was $<0.815$ his risk to die during the next five years was 2.3 times higher than among the rest of the patients 
( $p \leq 0.001)$. Correspondingly for AQ20 score $>7.5$ was associated with high mortality rate $(\mathrm{OR}=2.16, \mathrm{p} \leq$ $0.001)$. The clinical variables, which predicted both poor HRQoL and mortality, were $\mathrm{FEV}_{1}$, alcohol abuse, and cardiovascular diseases. HRQoL has been considered a potential component to the new multidimensional health status -measures in COPD [12]. Our results also suggest that HRQoL might provide a broader insight in predicting mortality than $\mathrm{FEV}_{1}$ alone.

Recent studies have shown clearly that COPD can no longer be assessed as a disease only involving the lungs [51]. Even though COPD has pulmonary and extrapulmonary manifestations both the generic and respiratory specific instruments gave surprisingly consistent results. The most important risk factors for poor HRQoL were identified by both instruments and by both analysis approaches applied. The risk factors for increased mortality were also partially overlapping and the HRQoL score was per se correlated with mortality. We have previously shown that when multiple HRQoL measures over five years are available for asthma and COPD patients constantly declining trends can be recognized with high probability [52]. In clinical practice the great benefit of the generic HRQoL instrument is that it allows the comparison of treatment interventions not only among COPD patients, but also in comparison to other patient groups suffering chronic diseases. Effectiveness of treatment options can be compared by using the 'quality adjusted life years' (QALY) measurement. Further this measurement allows us to consider the cost effectiveness of the treatment e.g. how much the treatments option costs per achieved QALY. It is an important additional feature in HRQoL studies, since disease burden of COPD is significant for public health care.

\section{Conclusion}

Our results suggest that the effect of co-morbidities in COPD is underestimated in regard of HRQoL. Psychiatric conditions, alcohol abuse, cardiovascular disease and lung function are comparably important in predicting the HRQoL of a COPD patient. These findings are further underlined by the higher prevalence of these conditions in this hospital based COPD cohort, when compared to age and gender matched general population. We chose for the study two short and easy to fill-in questionnaires and thus applicable also in clinical practice. The instruments have been validated in COPD and they have been shown to correlate to other more complex questionnaires. Being generic, 15D better captured the impact of co-morbidities while respiratory specific AQ20 was more sensitive to impaired lung function. Five-year mortality was significantly higher in patients with poor HRQoL measure at study baseline.

\section{Additional file}

Additional file 1: Table S1. Dimensions of HRQOL determined by 15D that differed significantly between males and females. Table S2 Dimensions of HRQOL determined by AQ20 that differed significantly between males and females. Table S3 Risk factors for mortality among COPD patients.

\section{Competing interests}

Jukka Koskela (JK) has no competing interests. Maritta Kilpeläinen (MK) has no competing interests. Henna Kupiainen (HK) has no competing interests. Witold Mazur (WM) has no competing interests. Harri Sintonen (HS) is the developer of the 15D and obtains royalties from electronic versions of the instrument. Marike Boezen (MB) has no competing interests. Ari Lindqvist $(\mathrm{AL})$ has no competing interests. The University of Groningen has received money for Professor Postma (DP) regarding an unrestricted educational grant for research from Astra Zeneca, Chiesi. Travel to ERS and/or ATS has been partially funded by Astra Zeneca, Chiesi, GSK, Takeda. Fees for consultancies were given to the University of Groningen by Astra Zeneca, Boehringer Ingelheim, Chiesi, GSK, Takeda and REVA. Travel and lectures in China paid by Chiesi. Tarja Laitinen (TL) has no competing interests.

\section{Authors' contributions}

JK carried out statistical analysis of data and drafted the manuscript. MK participated in acquisition of data and interpretation of the results. HK participated in acquisition of data. WM helped in drafting the manuscript. HS participated in interpretation of the results and drafting of the manuscript. MB helped in statistical analysis of the data. AL participated in acquisition of data. DP helped in interpretation of the results and drafting the manuscript. TL designed the study approach, analysis and interpretation of data. All authors read and approved the final manuscript.

\section{Acknowledgements}

The authors would like to thank clinical research nurses Ms Kerstin Ahlskog, Kirsi Elorinne, and Päivi Laakso for their skilful patient recruitment, Ms Tuula Lahtinen for the monitoring of the project, and students Siiri Carlson, Nelli Carlson, Piritta Rantanen repairing the data for analyses. This study was supported by the funding of Tekes (Intelligent Monitoring) and Foundation of the Finnish Anti-Tuberculosis Association.

\section{Author details}

${ }^{1}$ Clinical Research Unit for Pulmonary Diseases and Division of Pulmonology, Helsinki University Central Hospital, Helsinki, Finland. ${ }^{2}$ Division of Medicine, Department of Pulmonary Diseases and Clinical Allergology, Turku University Hospital and University of Turku, Turku, Finland. ${ }^{3}$ Department of Public Health, University of Helsinki, Helsinki, Finland. ${ }^{4}$ University of Groningen, University Medical Center Groningen, GRIAC Research Institute, Groningen, The Netherlands. ${ }^{5}$ Research Unit for Pulmonary Diseases, Helsinki University Central Hospital, Tukholmankatu 8C, PO Box 705, FI-00029 HUS Helsinki, Finland

Received: 23 May 2014 Accepted: 10 June 2014 Published: 19 June 2014

\section{References}

1. Agusti A, Soriano JB: COPD as a systemic disease. COPD 2008, 5(2):133-138. doi: 10.1080/15412550801941349; 10.1080/15412550801941349.

2. Fabbri LM, Luppi F, Beghe B, Rabe KF: Complex chronic comorbidities of COPD. Eur Respir J 2008, 31(1):204-212. doi: 10.1183/09031936.00114307; 10.1183/09031936.00114307.

3. van Manen JG, Bindels PJ, IJzermans CJ, van der Zee JS, Bottema BJ, Schade $\mathrm{E}$ : Prevalence of comorbidity in patients with a chronic airway obstruction and controls over the age of 40. J Clin Epidemiol 2001, 54(3):287-293

4. MacNee W: Systemic inflammatory biomarkers and co-morbidities of chronic obstructive pulmonary disease. Ann Med 2013, 45(3):291-300. doi: 10.3109/07853890.2012.732703; 10.3109/07853890.2012.732703.

5. Sin DD, Anthonisen NR, Soriano JB, Agusti AG: Mortality in COPD: role of comorbidities. Eur Respir J 2006, 28(6):1245-1257. doi: 10.1183/ 09031936.00133805 
6. Mannino DM, Thorn D, Swensen A, Holguin F: Prevalence and outcomes of diabetes, hypertension and cardiovascular disease in COPD. Eur Respir J 2008, 32(4):962-969. doi: 10.1183/09031936.00012408; 10.1183/09031936.00012408.

7. Vollmer WM, Gislason T, Burney P, Enright PL, Gulsvik A, Kocabas A, Buist AS Comparison of spirometry criteria for the diagnosis of COPD: results from the BOLD study. Eur Respir J 2009, 34(3):588-597. doi: 10.1183/09031936.00164608; 10.1183/09031936.00164608.

8. Ford ES, Wheaton AG, Mannino DM, Presley-Cantrell L, Li C, Croft JB: Elevated cardiovascular risk among adults with obstructive and restrictive airway functioning in the United States: a cross-sectional study of the national health and nutrition examination survey from 2007-2010. Respir Res 2012, 13:115-9921-13-115. doi: 10.1186/1465-9921-13-115; 10.1186/1465-9921-13-115.

9. Shavelle RM, Paculdo DR, Kush SJ, Mannino DM, Strauss DJ: Life expectancy and years of life lost in chronic obstructive pulmonary disease: findings from the NHANES III follow-up study. Int I Chron Obstruct Pulmon Dis 2009, 4:137-148

10. Mannino DM, Buist AS, Petty TL, Enright PL, Redd SC: Lung function and mortality in the United States: data from the first national health and nutrition examination survey follow up study. Thorax 2003, 58(5):388-393.

11. Alfageme I, Reyes N, Merino M, Reina A, Gallego J, Lima J, Palacios Z: The effect of airflow limitation on the cause of death in patients with COPD. Chron Respir Dis 2010, 7(3):135-145. doi: 10.1177/1479972310368692; 10.1177/ 1479972310368692

12. Domingo-Salvany A, Lamarca R, Ferrer M, Garcia-Aymerich J, Alonso J, Félez M, Khalaf A, Marrades RM, Monsó E, Serra-Batlles J, Antó JM: Health-related quality of life and mortality in male patients with chronic obstructive pulmonary disease. Am J Respir Crit Care Med 2002, 166(5):680-685. doi: 10.1164/rccm.2112043.

13. Schols AM, Slangen J, Volovics L, Wouters EF: Weight loss is a reversible factor in the prognosis of chronic obstructive pulmonary disease. Am J Respir Crit Care Med 1998, 157(6 Pt 1):1791-1797.

14. Konecny T, Somers K, Orban M, Koshino Y, Lennon RJ, Scanlon PD, Rihal CS: Interactions between COPD and outcomes after percutaneous coronary intervention. Chest 2010, 138(3):621-627. doi: 10.1378/chest.10-0300 10.1378/chest.10-0300

15. Sin DD, Man SF: Chronic obstructive pulmonary disease as a risk factor for cardiovascular morbidity and mortality. Proc Am Thorac Soc 2005, 2 (1):8-11. doi: 10.1513/pats.200404-032MS.

16. Vestbo J, Anderson W, Coxson HO, Crim C, Dawber F, Edwards L, Hagan G, Knobil K, Lomas DA, MacNee W, Silverman EK, Tal-Singer R: ECLIPSE investigators: Evaluation of COPD Longitudinally to Identify Predictive Surrogate End-points (ECLIPSE). Eur Respir J 2008, 31(4):869-873.

17. Calverley PM, Anderson JA, Celli B, Ferguson GT, Jenkins C, Jones PW, Yates JC, Vestbo J, TORCH investigators: Salmeterol and fluticasone propionate and survival in chronic obstructive pulmonary disease. N Engl J Med 2007, 356(8):775-789. doi: 10.1056/NEJMoa063070.

18. Decramer M, Celli B, Kesten S, Lystig T, Mehra S, Tashkin DP, UPLIFT investigators: Effect of tiotropium on outcomes in patients with moderate chronic obstructive pulmonary disease (UPLIFT): a prespecified subgroup analysis of a randomised controlled trial. Lancet 2009, 374(9696):1171-1178. doi: 10.1016/S0140-6736(09)61298-8; 10.1016/S0140-6736(09)61298-8.

19. de Torres JP, Casanova C, Hernandez C, Abreu J, Aguirre-Jaime A, Celli BR: Gender and COPD in patients attending a pulmonary clinic. Chest 2005, 128(4):2012-2016. doi: 10.1378/chest.128.4.2012.

20. Almagro P, Lopez Garcia F, Cabrera F, Montero L, Morchón D, Díez J, Soriano J, Grupo Epoc De La Sociedad Española De Medicina Interna: Comorbidity and gender-related differences in patients hospitalized for COPD. the ECCO study. Respir Med 2010, 104(2):253-259. doi: 10.1016/..rmed.2009.09.019.

21. Nurmatov U, Buckingham S, Kendall M, Murray SA, White P, Sheikh A, Pinnock H: Effectiveness of holistic interventions for people with severe chronic obstructive pulmonary disease: systematic review of controlled clinical trials. PLoS One 2012, 7(10):e46433. doi: 10.1371/journal. pone.0046433; 10.1371/journal.pone.0046433.

22. Hajiro T, Nishimura K, Jones PW, Tsukino M, Ikeda A, Koyama H, Izumi T: A novel, short, and simple questionnaire to measure health-related quality of life in patients with chronic obstructive pulmonary disease. Am J Respir Crit Care Med 1999, 159(6):1874-1878. doi: 10.1164/ajrccm.159.6.9807097.

23. Saarni SI, Harkanen T, Sintonen H, Suvisaari J, Koskinen S, Aromaa A, Lönnqvist J: The impact of 29 chronic conditions on health-related quality of life: a general population survey in finland using $15 \mathrm{D}$ and EQ-5D. Qual Life Res 2006, 15(8):1403-1414. doi: 10.1007/s11136-006-0020-1.
24. Jones PW: A self-complete measure of health status for chronic airflow limitation. the St. George's respiratory questionnaire. Am Rev Respir Dis 1992, 145(6):1321-1327.

25. Mazur W, Kupiainen $\mathrm{H}$, Pitkaniemi J, Kilpeläinen $\mathrm{M}$, Sintonen $\mathrm{H}$, Lindqvist $\mathrm{A}$, Kinnula VL, Laitinen T: Comparison between the disease-specific airways questionnaire 20 and the generic 15D instruments in COPD. Health Qual Life Outcome 2011, 9:4. doi: 10.1186/1477-7525-9-4.

26. Laitinen $T$, Hodgson U, Kupiainen $H$, Tammilehto L, Haahtela T, Kilpeläinen $M$, Lindqvist A, Kinnula VL: Real-world clinical data identifies genderrelated profiles in chronic obstructive pulmonary disease. COPD 2009, 6 (4):256-262.

27. Barley EA, Quirk FH, Jones PW: Asthma health status measurement in clinical practice: validity of a new short and simple instrument. Respir Med 1998, 92(10):1207-1214.

28. Alemayehu B, Aubert RE, Feifer RA, Paul LD: Comparative analysis of two quality-of-life instruments for patients with chronic obstructive pulmonary disease. Value Health 2002, 5(5):437-442.

29. Sintonen $\mathrm{H}$ : The $15 \mathrm{D}$ instrument of health-related quality of life: properties and applications. Ann Med 2001, 33(5):328-336.

30. Ritva K, Pekka R, Harri S: Agreement between a generic and diseasespecific quality-of-life instrument: the $15 \mathrm{D}$ and the SGRQ in asthmatic patients. Qual Life Res 2000, 9(9):997-1003.

31. Stavem K: Reliability, validity and responsiveness of two multiattribute utility measures in patients with chronic obstructive pulmonary disease. Qual Life Res 1999, 8(1-2):45-54.

32. Viljanen AA, Halttunen PK, Kreus KE, Viljanen BC: Spirometric studies in non-smoking, healthy adults. Scand I Clin Lab Invest Supp/ 1982, 159:5-20

33. Heistaro S: Methodology Report, Health 2000 Survey: 2008. Helsinki: National Public Health Institute; 2008.

34. Bestall JC, Paul EA, Garrod R, Garnham R, Jones PW, Wedzicha JA: Usefulness of the Medical Research Council (MRC) dyspnoea scale as a measure of disability in patients with chronic obstructive pulmonary disease. Thorax, 54:581-586. doi: 10.1136/thx.54.7.581

35. Sintonen $\mathrm{H}$ : Outcome measurement in acid-related diseases. Pharmacoeconomics 1994, 5(3):17-26. http://dx.doi.org/10.2165/00019053199400053-00005. doi: 10.2165/00019053-199400053-00005

36. Vestbo J, Hurd SS, Agusti AG, Jones PW, Vogelmeier C, Anzueto A, Barnes PJ, Fabbri LM, Martinez FJ, Nishimura M, Stockley RA, Sin DD, RodriguezRoisin R: Global strategy for the diagnosis, management, and prevention of chronic obstructive pulmonary disease: GOLD executive summary. Am J Respir Crit Care Med 2013, 187(4):347-365.

37. Putcha N, Puhan MA, Hansel NN, Drummond MB, Boyd CM: Impact of comorbidities on self-rated health in self-reported COPD: an analysis of NHANES 2001-2008. COPD 2013, 10(3):324-332. doi: 10.3109/ $15412555.2012 .744963 ; 10.3109 / 15412555.2012 .744963$.

38. Feary JR, Rodrigues LC, Smith CJ, Hubbard RB, Gibson JE: Prevalence of major comorbidities in subjects with COPD and incidence of myocardial infarction and stroke: a comprehensive analysis using data from primary care. Thorax 2010, 65(11):956-962. doi: 10.1136/thx.2009.128082; 10.1136/ thx.2009.128082

39. Lusuardi M, Garuti G, Massobrio M, Spagnolatti L, Bendinelli S: Heart and lungs in COPD. close friends in real life-separate in daily medical practice? Monaldi Arch Chest Dis 2008, 69(1):11-17.

40. Rodriguez LA, Wallander MA, Martin-Merino E, Johansson S: Heart failure, myocardial infarction, lung cancer and death in COPD patients: A UK primary care study. Respir Med 2010, 104(11):1691-1699. doi: 10.1016/j. rmed.2010.04.018; 10.1016/.j.rmed.2010.04.018.

41. Halme JT, Seppa K, Alho H, Pirkola S, Poikolainen K, Lönnqvist J, Aalto M: Hazardous drinking: prevalence and associations in the finnish general population. Alcohol Clin Exp Res 2008, 32(9):1615-1622. doi: 10.1111/j.15300277.2008.00740.x; 10.1111/j.1530-0277.2008.00740.x.

42. Ryan M, Merrick EL, Hodgkin D, Horgan CM, Garnick DW, Panas L, Ritter G, Blow FC, Saitz R: Drinking patterns of older adults with chronic medical conditions. J Gen Intern Med 2013, doi: 10.1007/s11606-013-2409-1.

43. Kastarinen $M$, Antikainen R, Peltonen M, Laatikainen $T$, Barengo NC, Jula A, Salomaa V, Jousilahti P, Nissinen A, Vartiainen E, Tuomilehto J: Prevalence, awareness and treatment of hypertension in Finland during 1982-2007. J Hypertens 2009, 27(8):1552-1559. doi: 10.1097/HJH.0b013e32832c41cd; 10.1097/HJH.0b013e32832c41cd

44. Ferrer M, Alonso J, Morera J, Marrades RM, Khalaf A, Aguar MC, Plaza V, Prieto L, Antó JM: Chronic obstructive pulmonary disease stage and 
health-related quality of life. the quality of life of chronic obstructive pulmonary disease study group. Ann Intern Med 1997, 127(12):1072-1079.

45. van Manen JG, Bindels PJ, Dekker EW, ljzermans CJ, Bottema BJ, van der Zee JS, Schadé E: Added value of co-morbidity in predicting health-related quality of life in COPD patients. Respir Med 2001, 95(6):496-504.

46. Jones PW, Brusselle G, Dal Negro RW, Ferrer M, Kardos P, Levy ML, Perez T, Soler-Cataluña JJ, van der Molen T, Adamek L, Banik N: Health-related quality of life in patients by COPD severity within primary care in Europe. Respir Med 2011, 105(1):57-66. doi: 10.1016/j.rmed.2010.09.004.

47. Burgel PR, Escamilla R, Perez T, Carré P, Caillaud D, Chanez P, Pinet C, Jebrak G, Brinchault G, Court-Fortune I, Paillasseur JL, Roche N, INITIATIVES BPCO Scientific Committee: Impact of comorbidities on COPD-specific health-related quality of life. Respir Med 2013, 107(2):233-241. doi: 10.1016/j.rmed.2012.10.002

48. Watson L, Schouten JP, Löfdahl CG, Pride NB, Laitinen LA, Postma DS: Predictors of COPD symptoms: does the sex of the patient matter? Eur Respir J 2006, 28(2):311-318.

49. Blanco-Aparicio M, Vazquez I, Pita-Fernandez S, Pertega-Diaz S, VereaHernando H: Utility of brief questionnaires of health-related quality of life (airways questionnaire 20 and clinical COPD questionnaire) to predict exacerbations in patients with asthma and COPD. Health Qual Life Outcome 2013, 11:85-7525-11-85. doi: 10.1186/1477-7525-11-85; 10.1186/1477-7525-11-85.

50. Ryynanen OP, Soini EJ, Lindqvist A, Kilpelainen M, Laitinen T: Bayesian predictors of very poor health related quality of life and mortality in patients with COPD. BMC Med Inform Decis Mak 2013, 13:34-6947-13-34. doi: 10.1186/1472-6947-13-34; 10.1186/1472-6947-13-34.

51. Cazzola M, MacNee W, Martinez FJ, Rabe KF, Franciosi LG, Barnes PJ, Brusasco V, Burge PS, Calverley PM, Celli BR, Jones PW, Mahler DA, Make B, Miravitlles M, Page CP, Palange P, Parr D, Pistolesi M, Rennard SI, Rutten-van Mölken MP, Stockley R, Sullivan SD, Wedzicha JA, Wouters EF, American Thoracic Society; European Respiratory Society Task Force on outcomes of COPD: Outcomes for COPD pharmacological trials: from lung function to biomarkers. Eur Respir J 2008, 31(2):416-469. doi: 10.1183/ 09031936.00099306; 10.1183/09031936.00099306.

52. Koskela J, Kupiainen H, Kilpelainen M, Lindqvist A, Sintonen H, Pitkäniemi J, Laitinen T: Longitudinal HRQoL shows divergent trends and identifies constant decliners in asthma and COPD. Respir Med 2014, 108:463-471.

doi:10.1186/1471-2466-14-102

Cite this article as: Koskela et al: Co-morbidities are the key nominators of the health related quality of life in mild and moderate COPD. BMC Pulmonary Medicine 2014 14:102.

\section{Submit your next manuscript to BioMed Central and take full advantage of:}

- Convenient online submission

- Thorough peer review

- No space constraints or color figure charges

- Immediate publication on acceptance

- Inclusion in PubMed, CAS, Scopus and Google Scholar

- Research which is freely available for redistribution 